\title{
Effects of Substitute Fuels on Automotive Engines
}

\author{
By Clarence S. Bruce, Jesse T. Duck, and A. R. Pierce
}

\begin{abstract}
Tests were made to determine the operating characteristics of automotive engines with respect to cylinder wear, carbon deposits, life of accessories, and vapor lock. Fuels circulating through standard type pumps for a period equivalent to 200,000 miles had no visible effect on pump diaphragms. Cylinder wear with various fuels was determined by an optical instrument, the McKee wear gage. Wear is determined from changes in lengths of indentations made in cylinder walls with a precisely shaped diamond tool. The wear with alcohol was about half that with leaded gasoline. Carbon deposits also were much lower. There was no indication of dilution of crankcase oil by alcohol. The temperature limits for operation without vapor lock were established for various blends of alcohol with ether and with acetone.
\end{abstract}

\section{Introduction}

During the early months of the war, transportation of essential gasoline supplies to our allies became a serious problem. As enemy submarine warfare became more and more aggressive, petroleum reserves in these countries dwindled. Operation of automotive equipment with substitute fuels became common. However, equipment designed for use with gasoline frequently required modification before substitutes could be successfully used, and many operational difficulties were experienced.

In 1942 the National Bureau of Standards began a comprehensive study of the problems involved in the use of substitute motor fuels. This investigation was carried out at the request of the Board of Economic Warfare (later the Foreign Economic Administration) and included studies of the following special problems: (1) Effects of variations in compression ratios, (2) knock ratings, (3) power and fuel consumption with standard type automotive engines, (4) engine tests of gaseous fuels, (5) the effects of mixture distribution on engine performance, (6) starting characteristics at low temperatures and at altitudes, (7) fuel-pump life, cylinder wear, and corrosion, and (8) vapor lock with blends. The results of the first six studies $[1 \text { to } 6]^{1}$ listed above have been reported in the

1 Figures in brackets indicate the literature references at the end of this paper.
Journal of Research of the National Bureau of Standards. This report is the last of the series and includes all phases of the work not covered by the six earlier publications. The field to be investigated is very large, and some parts of it could not be completed in the time available. Further study of the causes of cylinder wear and methods of measuring it seem especially desirable. The test results support the widely accepted theory that much cylinder wear is due to corrosion occurring in low-temperature operation. A brief summary of each of the preceding papers follows:

RP1660 Single cylinder engine tests of substitute motor fuels.-Single-cylinder engine tests of nonhydrocarbon fuels and gasoline at fixed compression ratio and at the compression ratio for trace knock for each fuel show no material difference in performance other than those associated with differences in heats of combustion and of vaporization. All of the nonhydrocarbon fuels could be used at compression ratios higher than was permissible with gasoline, with corresponding increases in power and thermal efficiency.

RP1673 Knock ratings of gasoline substitutes.-Knock ratings of gaseous paraffins and olefins through $\mathrm{C}_{4}$ and of carbon monoxide were determined by current motor and aviation test methods. Auxiliary apparatus and modifications of test engines necessary to rate gases are described.

Antiknock qualities of ethyl and normal butyl alcohol, and acetone, both alone and in blends were determined by current motor fuel rating procedures. Blending characteristics of these materials with straight-run gasoline and naphthas were investigated.

The tests indicated that blends containing up to 45percent diethyl ether in alcohol should give relatively 
knock-free performance under conditions of steady operation.

RP1681 The utilization of nonpetroleum fuels in automotive engines. - A number of substitute fuels and blends were tested to determine their relative efficiencies in operation of common types of engines. The tests showed that the maximum power developed with alcohol and with some of the other fuels was slightly greater than with gasoline. The specific fuel consumption with the various fuels was approximately in inverse proportion to the heat of combustion. Analysis showed that the mixture distribution was less uniform with the substitute fuels than with gasoline. Tests made with low-proof alcohols showed that an engine can be operated on a blend as low as 70-proof, but it is ordinarily impractical to use a blend much below 190-proof because of the excessive volumes required.

RP1698 Engine test with producer gas.-Bench tests with a four-cylinder stationary combustion engine were made using gasoline and producer gas from charcoal as fuels. The maximum power of an engine operating on producer gas is about 55 percent of that developed by the same engine when gasoline is used as a fuel. About $11.4 \mathrm{lbs}$. of charcoal is equivalent to 1 gallon of gasoline. Spark setting studies show that when operating on producer gas the spark should be advanced beyond the setting for maximum power with gasoline.

RP1712 An analysis of the effects of fuel distribution on engine performance.-From an empirical equation based on single cylinder engine test data, and relating engine power to fuel consumption, engine performance curves are derived analytically for typical examples of poor distribution. Investigation of the resulting information shows that the minimum specific fuel consumption is a satisfactory criterion of distribution quality.

RP1811 Cold-starting abilities of various substitute fuels.Tests of various nonhydrocarbon fuels in a standard eight-cylinder engine showed the starting abilities of some single constituent fuels to be rather limited, but the addition of small percentages of more volatile fuels lowered the minimum starting temperature to a very marked degree.

A limited number of tests under altitude conditions also showed a further reduction in minimum starting temperature for each of the fuels used. This should compensate to some degree for the lower average temperatures usually encountered at higher altitudes, so that for any one area it would be possible to obtain satisfactory starting with a minimum number of blend changes.

In the six papers previously submitted it is indicated that several of the substitute fuels compare favorably with gasoline in general performance. However, most of the test data given relates to performance during comparatively short periods of operation - not long enough to show definitely the effects of physical and chemical properties of the fuels on the engines and their operation. In this report these properties are considered as they affect (1) life of fuel pumps, (2) relative rate of evaporation of fuels, (3) cylinder wear and corrosion, (4) combustion chamber deposits, (5) crankcase oil dilution, and (6) temperature limits for operation without vapor lock.

\section{Life of Fuel Pumps}

As it was believed possible that parts of the fuel pump might deteriorate through corrosive or solvent action of some of the substitute fuels used, a number of diaphragm type pumps of a given make were set up to deliver a quantity of fuel that would be comparable to normal life operation in an automobile. Six fuel pumps were mounted as shown in figure 1 . The pumps were

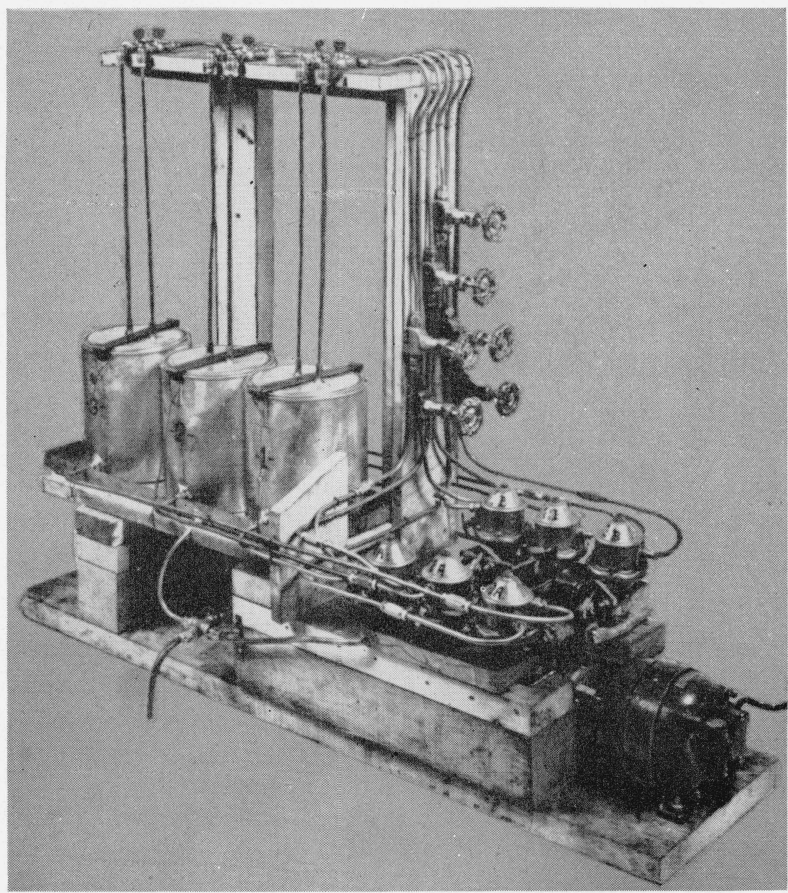

FIG URE 1. Fuel-pump mounting for pump life and evaporation tests.

operated by an oscillating arm driven by an electric motor. The stroke of each pump was adjusted so that the unrestricted flow was $600 \mathrm{ml}$ per minute. The outlet of each pump was then throttled until the delivery was $300 \mathrm{ml}$ per minute, approximately the requirement for operation at $70 \mathrm{mph}$ on gasoline. The test setup comprised three 1-gallon tanks with two pumps connected to draw fuel from and return it to each tank through 1/4-in. copper tubes discharging $1 \frac{1}{2}$ in. above a designated fuel level in the tanks. The open ends of the discharge lines were conducted through 
$1 \frac{1}{4}$-in. lengths of $3 / 8$-in. copper tubing. By this arrangement, a small amount of aeration, as well as a vent for breathing, was provided. Each tank was filled to the designated level at the beginning of the test. The pumps were equipped with standard valves and diaphragms, the latter being of the paint-base drying-oil type. The pumps operated without failure for $3,500 \mathrm{hr}$ over a period of $5 \mathrm{mo}$. This is equivalent to more than 200,000 miles of operation, and is considered satisfactory performance as it is somewhat more than the life of the average automobile. Diaphragms impregnated with synthetic rubber were not tested, but it is believed that they would show at least equal resistance to these fuels and blends.

\section{Relative Rate of Evaporation of Fuels}

The fuel-pump endurance runs afforded an opportunity to find the relative evaporation losses of the test fuels as compared with gasoline. In each test, gasoline was run in one unit so that the effect of ambient conditions might be minimized by correcting to gasoline evaporation. Figure 2 shows the evaporation of gasoline during a 24-hr run. As each unit has a capacity of $3,100 \mathrm{ml}$ of fuel, the loss is about one-fourth of the total volume in $24 \mathrm{hr}$. All of the relative evaporation loss values given in the following table are based on the loss during $6 \mathrm{hr}$ of operation of the endurance run equipment. This corresponds to an assumed tank loss of 10 percent with gasoline, as shown in figure 2 .

TABLE 1. Relative evaporation loss of fuels

\begin{tabular}{|l|c|}
\hline \multicolumn{1}{|c|}{ Fuel } & $\begin{array}{c}\text { Relative loss } \\
\text { rate }\end{array}$ \\
\hline Gasoline & \\
Acetone & 52 \\
$n$-Butanol & 28 \\
Alcohol $(190$ proof) & 1 \\
$72 \%$ acetone, $28 \%$ 190-proof alcohol & 10 \\
$12 \%$ ether, $88 \%$ 190-proof alcohol a & \\
& \\
\hline a Blend to start at $10^{\circ} \mathrm{F}$. & 20 \\
\hline
\end{tabular}

a Blend to start at $10^{\circ} \mathrm{F}$.

It is seen that the evaporation loss with each of these fuels is materially less than with gasoline. The evaporation loss of the acetone-alcohol blend is somewhat higher than for either of the pure fuels. The ASTM distillation curves for the two blends are shown in figure 3.

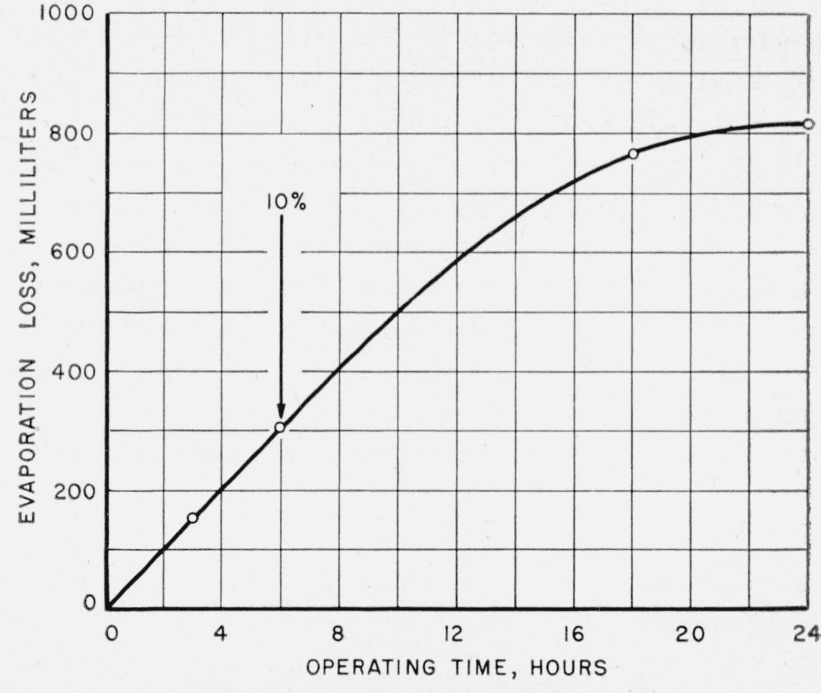

Figure 2. Gasoline evaporation and pump operating time.

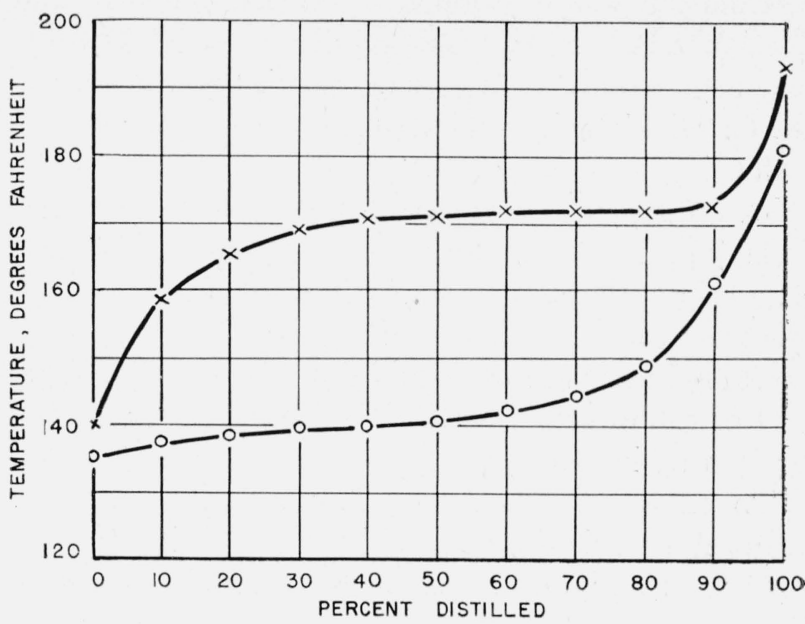

Figure 3. ASTM distillation curves for fuel blends.

Distillation was started at $10^{\circ} \mathrm{F}$. $\bigcirc, 72$-percent acetone in 190 -proof alcohol; $\times, 12$-percent ether in 190-proof alcohol.

\section{Cylinder Wear and Corrosion}

\section{Types of Cylinder Wear}

Cylinder wear may be of three types: (1) Abrasion due to foreign particles in the oil film or intake air, (2) attrition caused by metal-to-metal contact of the pistons or rings and the cylinder bore, and (3) corrosive action on the pistons, rings, or cylinder wall.

Air cleaners and oil filters and changes in engine design have brought about a considerable reduction in cylinder wear during recent years. It is reasonable to assume that the greater part of the 
reduction in wear must be due to better protection from abrasion and attrition. It is believed that a large proportion of cylinder wear at present is due to corrosion, but no satisfactory method has been developed to determine how much. Operation of engines with various substitute fuels and with gasoline may offer a good basis for evaluation of corrosion wear, as all conditions that may affect abrasion and erosion are equal. A substantial reduction in cylinder wear with a substitute fuel would indicate more corrosion with gasoline and vice versa. In this connection it has been found [7] that a large proportion of the wear with leaded gasoline is probably due to the presence of the lead compound.

\section{Development of the Method}

The method used for measuring wear in this investigation was developed a few years ago at the National Bureau of Standards by S. A. McKee at the suggestion of and with the collaboration of H. C. Dickinson. The method utilizes a form of indenting tool similar to that developed by Frederick Knoop, also of the National Bureau of Standards, [8] for determining the hardness of materials. The original wear test apparatus was designed for the measurement of wear in the cylinders of aircraft engines. A full description of the instrument and of the development of the method is given in a paper by McKee [9].

The method is covered by U. S. Patent 2,233,403, granted to Dickinson and McKee on March 4, 1941, and assigned by them to the United States Government. The instrument was modified for use with automobile engines and manufactured by the American Instrument Co., Silver Spring, Md., under license issued by the Secretary of Commerce.

With the McKee gage the wear is determined on the cylinder wall by observing changes in length of indentations made on the wall with a precisely shaped indenting tool. The length of the indentation is accurately measured by a special microscope, and its depth is computed from the length measured. The amount of wear at any given point is considered to be the difference in the computed depths of an indentation before and after a period of operation.

Wear observations made under good conditions with this apparatus are reproducible to $0.00002 \mathrm{in}$., and amounts smaller than this can be detected.

\section{Description of Wear Test Instrument}

The instrument is shown in detail in figure 4 . There are three essential parts: (1) A precisely shaped diamond indenting tool.-The indenter can be adjusted to make marks from $1 / 2$ to $2 \mathrm{~mm}$ in length. In practice a mark about $1 \mathrm{~mm}$ long has been found convenient. When the indentations are made in the cylinder wall, the indenter is held securely in place by: (2) an indentation locater. The core of the locater can be rotated within its

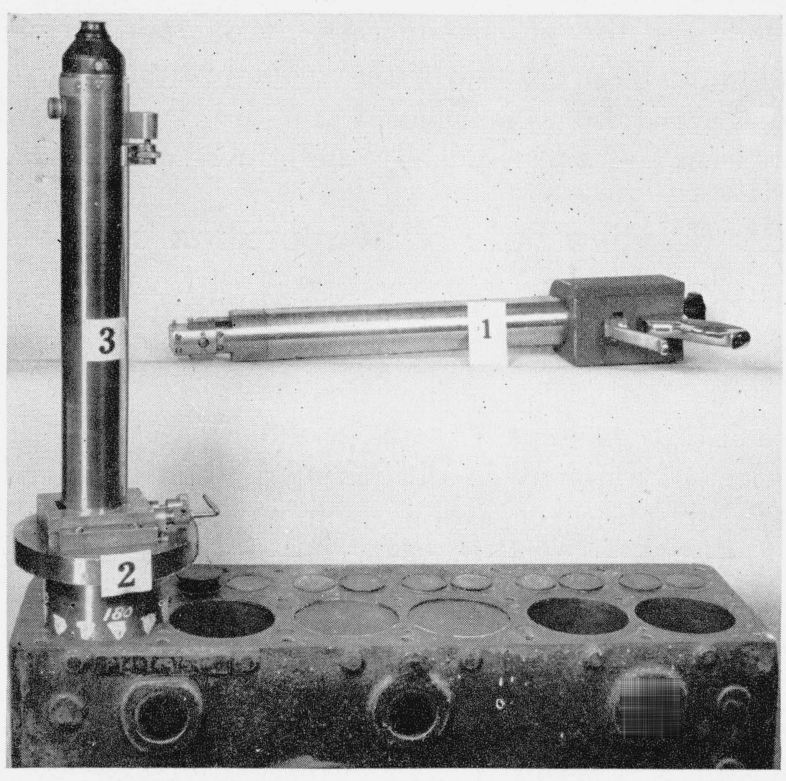

Figure 4. McKee wear gage.

1, Indenting tool; 2 , indentation locator; 3 , microscope.

base so that marks can be made at 30-degree intervals around the cylinder wall. (3) A microscope.The microscope fits into the locater exactly in the same way as the indenter, so that when the locater is in the indenting position the indentation is in the field of view. A calibrated scale is superimposed on the image of the indentation so that the length of the indentation is represented by a given number of scale units. Each scale unit represents about $0.01 \mathrm{~mm}$ of length. It has been determined that the error of the scale does not exceed 0.2 percent.

\section{Analysis of the Indentation}

As the depth of the indentation is a function of its length, the depth at any given time may be computed from the length measured on the optical scale. The wear during any period of operation 
is represented by the difference in the depths computed before and after the operating period.

The indenter is a pyramid whose base has the shape of a rhombus. The longitudinal axis of the base is several times longer than the transverse axis. The indentation as seen in the microscope is not visible in depth but is seen as an outline of its base. The four triangular faces of the pyramid have equal apex angles.

The width of the indentation has no significance in computations of depth. The depth is computed from the length of the image of the indentation as seen on the optical scale of the microscope. The computations are based on the imaginary triangle formed by joining the ends of the indentation with its apex. In figure 5 the line

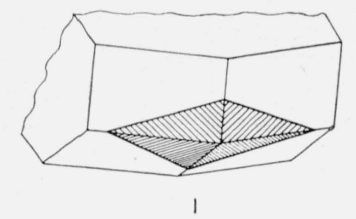

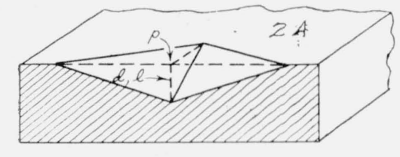

$2 \mathrm{~A}$
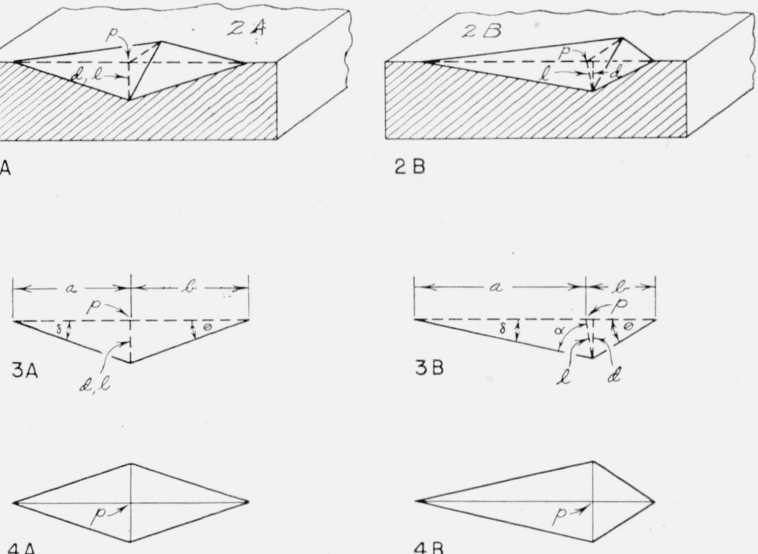

$2 \mathrm{~B}$
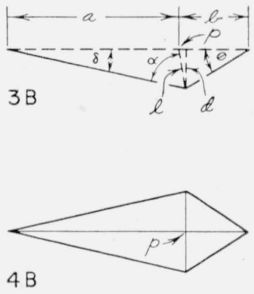

FIgURE 5. Schematic drawing of indentation made by McKee wear gage.

$(a+b)$ represents the length of the indentation, which is divided into the segments $a$ and $b$ by the transverse axis of the rhombus that is seen in the visible image of the indentation. The significant factors involved in the mathematical analysis are the relations of the depth of the indentation to the lengths of the segments $a$ and $b$ and to the sines and tangents of the angles $\theta$ and $\delta$. If the indentation is symmetrical, $a=b$, and $\delta=\theta=4^{\circ}$ $17^{\prime}$. (The angle at the apex of the indenter is by actual measurement $171^{\circ} 26^{\prime}$.)
Therefore when the indentation is symmetrical

$$
\begin{aligned}
& d=b \tan 4^{\circ} 17^{\prime} \\
& d=\frac{a+b}{2} \tan 4^{\circ} 17^{\prime} \\
& d=0.0749 \frac{(a+b)}{2}=0.03745(a+b) .
\end{aligned}
$$

The graduated scale of the microscope used in this work is divided into 100 divisions, each $0.0099 \mathrm{~mm}$ long. Using these values, we find that $d=0.0000146(a+b)$ in. if $a$ and $b$ are expressed in McKee gage scale divisions.

If the indentation is not symmetrical, there is a decrease in its depth due to asymmetry. This type of indentation is shown in figure 5 by drawings $2 \mathrm{~B}, 3 \mathrm{~B}$, and $4 \mathrm{~B}$. The loss in depth may occasionally be as much as 5 percent, although most cases in actual practice are found to be nearly symmetrical. (In $94 \%$ of a typical group of marks, the correction for asymmetry was less than $0.5 \%$.)

Figure 6 shows the magnitude of the correction

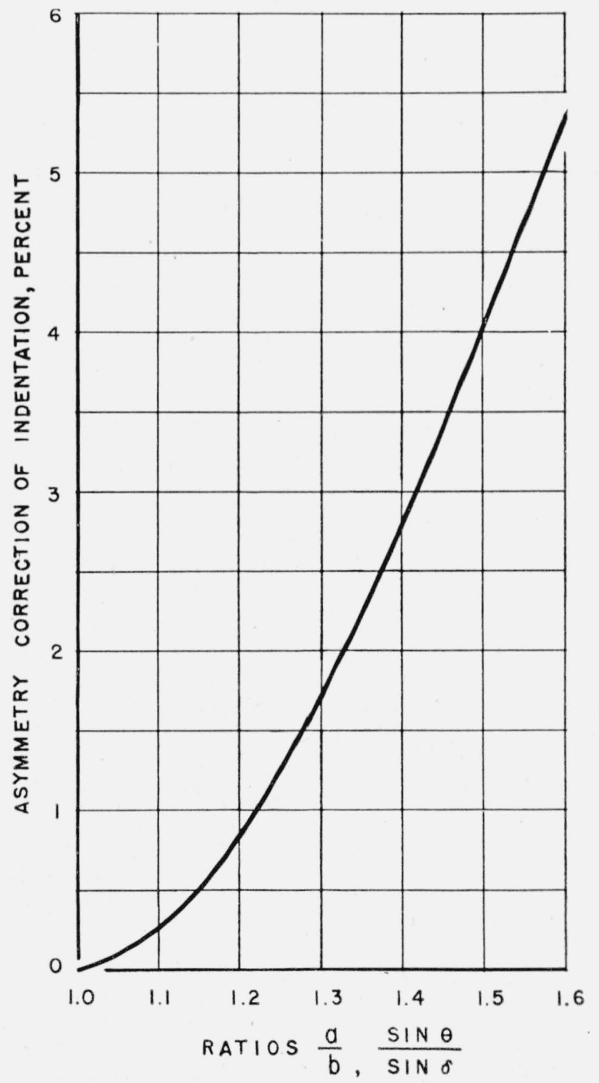

Figure 6. Correction for asymmetry of the indentation. 
necessary for various amounts of asymmetry. The mathematical analysis on which this chart is based is given in the appendix.

As the indentations were made with the long axis along the curved surface of the cylinder wall, there is a correction for curvature. This varies from 2 to 8 percent, depending on the length of the indentation and the size of the cylinder. The value of the correction is closely approximated by the expression $(a+b)^{2} / 8_{\mathrm{r}}$, where $(a+b)$ is the length of the mark, and $r$ is the radius of the cylinder.

The indentation is somewhat distorted by springback of metal after the indenter is removed. Our data indicate that this springback will average about 20 percent in cast-iron cylinders. This will be discussed further below.

\section{Corrections in Instrument Readings}

Within certain limits, metal pushed out of position by an indenting tool will tend to return to its original position, but after the limit of elasticity is reached at least part of the deformation is permanent. The shape of the indentation will therefore not be the same as that of the indenter, because some of the metal has a tendency to spring back when the indenting tool is removed. The final impression may depend on hardness, homogeneity, and elasticity of the metal, and the rate at which the load is applied. Because of these factors, the relation between the length of the mark (indentation) and its depth varies. This relation may change as the mark wears away. It is believed that in homogeneous materials the depth of the mark cannot be more than the theoretical depth represented by the shape of the indenter before its removal.

No satisfactory method was developed to determine accurately the depth of individual marks. All corrections used in analysis of the test results were based on averages. However, the American Instrument Co. furnished a chart in which the corrections were based on the Knoop hardness of the material. In practice this chart could not be used, because the Knoop hardness could not be determined accurately in an engine cylinder.

The calibration for springback of metal in the indentation is shown on figure 7 . This plot was derived as follows: Flat metal blocks bearing a considerable number of indentations made with a McKee indenter were lapped off in measured

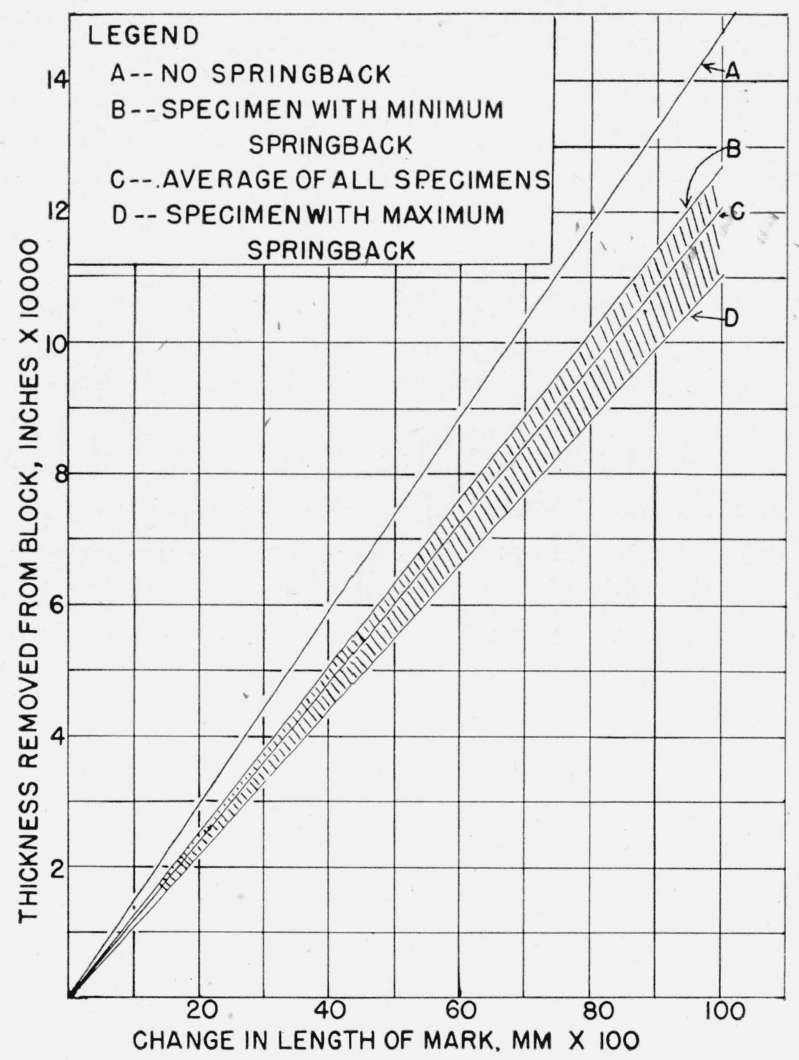

Figure 7. Calibration of wear gage for cast iron and steel specimens.

A, No springback; B, specimen with minimum springback; C, average of all specimens; D, specimen with maximum springback.

increments, the length of each mark being measured with the McKee microscope after each lapping. In this way a plot of the average loss in length of the mark against loss in thickness of the block was obtained for representative samples of cast iron of a wide range of hardness. Another similar set of measurements was made from a section of steel cylinder liner of the type used in test engine 3 . The thickness of the blocks was measured with a special type of gage accurate to $0.00001 \mathrm{in}$. The blocks were lapped parallel to within about 0.00001 in. Therefore, a thickness measurement might be locally in error by 0.00002 in., although the error would normally be smaller. As this local error would be a considerable part of any measurement that would normally be made with the McKee gage, it was not known whether variations in changes of length of individual marks were due to differences in the proportion of springback or to slight local differences in the amount of metal lapped off. It was therefore 
decided that the correction should be applied to a group of several indentations.

It was expected that the amount of springback would vary with the hardness of the metal. However in the work done in the investigation of cast iron specimens, no relation of springback to hardness of the metal was found. The maximum springback found was 25 percent, (fig. 7 , curve $D$ ) the minimum 15 percent, (curve $B$ ) and the average 18 percent, (curve $C$ ). The correction found for the steel cylinder liner was 16.5 percent. The probable maximum error in the use of the average value of 18 percent would therefore be about 7 percent.

Skilled operators were able to agree on individual measurements with McKee microscope within 0.01 of the length of the scale, usually within 0.005 . When the marks are considered as a group, the error of reading is not therefore believed to be large enough to be considered in relation to the correction for springback. The length of the scale represents $0.00146 \mathrm{in}$. of depth before corrections for springback are made.

The precision of the method may be illustrated by the following example. Assuming that errors of reading the instrument are nearly eliminated by use of averages, the average length of the marks on cylinder No. 2 at the start of a wear measurement is 85 scale divisions. After a period of engine operation, the average length of the same marks is 75 scale divisions. The net average change in length is 10 scale divisions. The average original depth of the marks allowing for 18 percent correction for springback is $0.00102 \mathrm{in}$. The average depth at the end of the operating period is $0.00090 \mathrm{in}$. The change in depth (wear) is $0.00012 \mathrm{in}$. The correction for springback is believed to be precise within 7 percent. The error in reading, 0.0001 in. of wear, is therefore believed to be less than $0.00001 \mathrm{in}$. when the marks are considered as a group.

\section{Sensitivity of McKee Wear Gage}

The McKee indenter is of greatest value in measurement of small increments of wear. The limit to which inside micrometers may be used with any degree of accuracy is probably about 0.0001 in. The accuracy of measurements made with a micrometer is affected to a considerable extent by the temperatures at which measurements are taken. The expansion of metal over a 3 - to 4 -in. diameter may be as much as 0.0001 in. for a temperature difference of $3 \mathrm{deg}$ C. A further source of trouble when micrometers are used is distortion of the cylinder walls. With the McKee wear gage, both difficulties are very nearly eliminated. The change in depth of an indentation due to a temperature change of $3 \mathrm{deg} \mathrm{C}$ is less than one one-hundredth of 1 percent. With micrometers, errors in measurement will vary in proportion to the diameter of the cylinder. In the use of the McKee wear gage, only the amount of metal worn from the cylinder wall is measured. The change in diameter of the cylinder not being a significant factor, distortion of the cylinders may affect the wear at a given point, but the accuracy of measurements is not affected.

\section{Test Equipment and Operating Conditions}

Five 1942 model engines, of three different makes, were used in the tests. The engines were direct-connected to dynamometers or electric generators and were operated $24 \mathrm{hr}$ a day on a common test cycle that included 20 min operating time and a 10-min shut down in each half-hour. The 20-min operating time consisted of four 5min periods, during which the engine was operated for $3 \frac{1}{2}$ min under conditions equivalent to road operation at about $40 \mathrm{mph}$, then was idled for $1 \frac{1}{2} \mathrm{~min}$ at $500 \mathrm{rpm}$. During the shut-down period cold water was forced through the cooling systems of the engines and through special cooling coils in the oil pan, in order to have normal starting conditions at the beginning of each operating period. Throttle operations of the engines were controlled simultaneously by solenoids operated by an electric clock. Speeds and temperatures were recorded after $15 \mathrm{~min}$ of operation.

A recording vacuum gage was connected to the intake manifold of each engine. As the manifold pressure is a direct function of the throttle position at any given speed, an excellent record of events of operation was obtained. A typical 24-hr recording is reproduced in figure 8 . Temperature and speed readings for a typical 30-min cycle are shown in figure 9.

Twelve indentations were made at each of four levels ( $1 / 2$ in., $3 / 4$ in., 1 in., and $1 \frac{1}{4}$ in. below the top of the block in each cylinder), one mark on the center line of the thrust face and the others spaced 30 degrees apart around the cylinder. The lengths of the indentations were measured with the McKee 


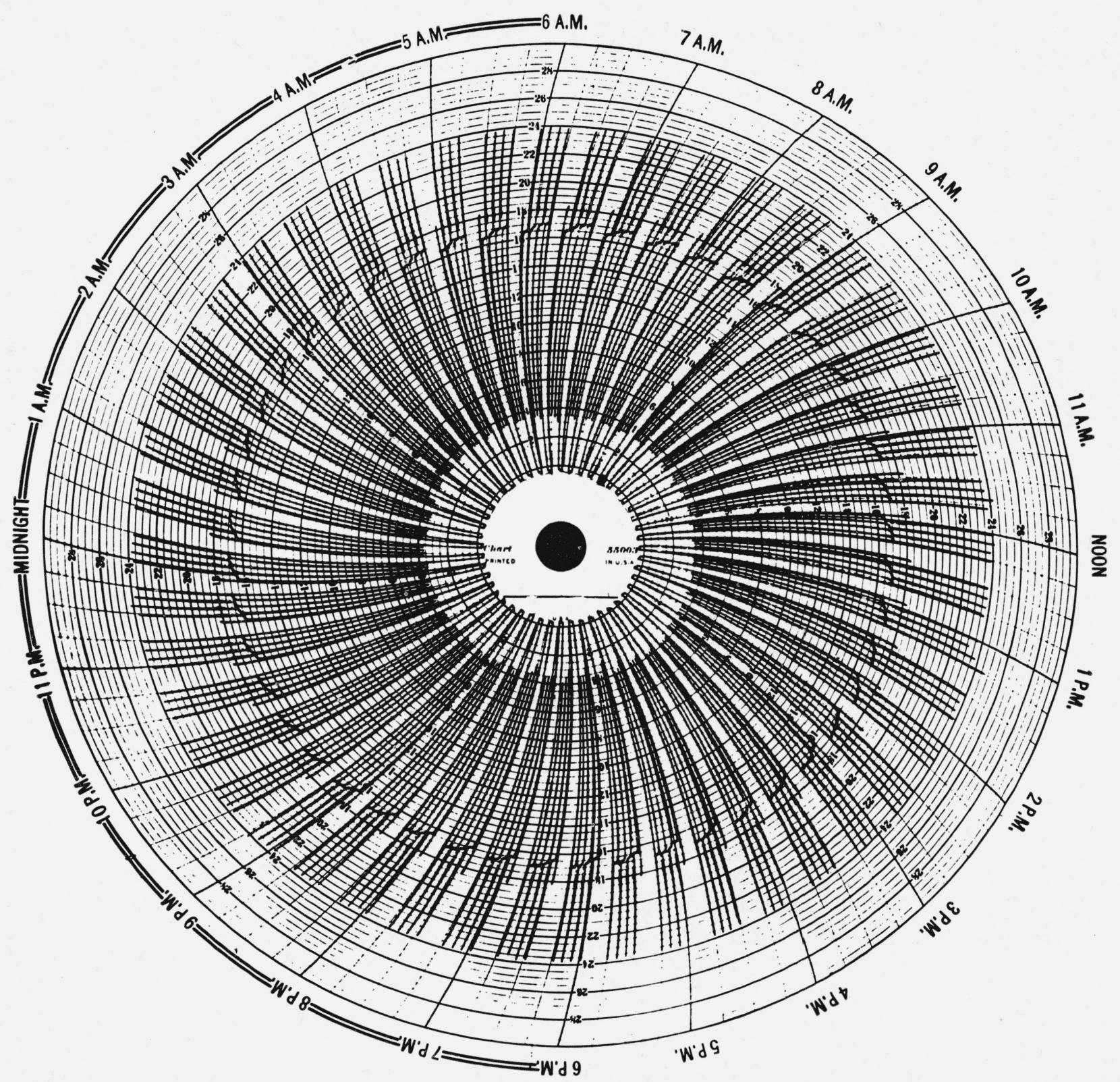

FIGURE 8. Bristol vacuum chart after 24 hours of operation of test engine.

gage before the start of the test and after $144 \mathrm{hr}$ of operation. The indentations were made with the long axis perpendicular to the axis of the cylinder.

It was soon discovered that the temperature of the water circulated through the engine during the 10-min shut-down period had a significant effect on the cylinder wear. Thereafter the circulated cooling water was drawn from two storage tanks in which the temperature could be accurately controlled at any desired level.

\section{Test Results}

There was much variation in wear at the various points. Some of this may be attributed to (1) Slight local depressions and elevations of the cylinder walls, (2) changes in contour of the cylinder walls resulting from unequal torque in tightening of the cylinder head bolts, (3) location of the marks with reference to the height on the cylinder wall or to the circumference of the cylin- 


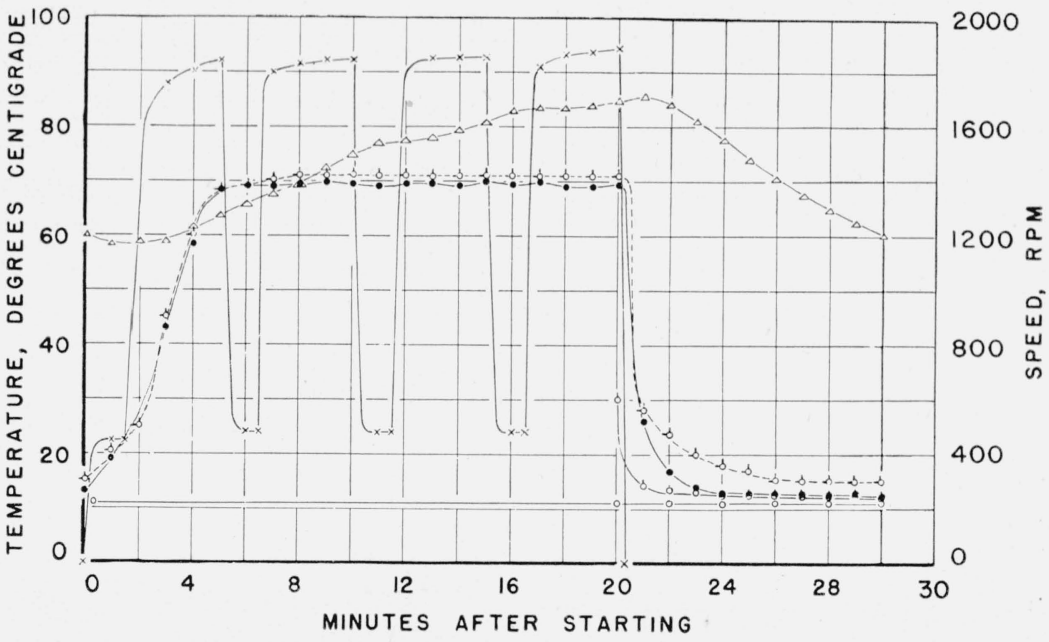

FIGURE 9. Engine temperatures during typical wear-test operating cycle.

$\bigcirc$, Tapwater; $\dot{O}$, outlet, oil cooler; $\mathbf{0}$, outlet, cylinder head; $-\dot{O}$, jacket water; $\triangle$. crankcase oil; $\times$, speed.

der, and (4) inhomogeneities in the composition of the metal.

The cylinder wear was somewhat greater when the engines were operated on gasoline than when some of the substitute fuels were used. There was, however, a considerable variation in the amount of wear from week to week. This variation could not always be accounted for by known factors, but was found to depend to some extent on the temperature of the cooling water, cycle of operation, and other factors. These factors will be discussed further below.

The wear around the circumference of the cylinder did not always follow a consistent pattern. The least amount of wear in nearly every case appeared on the side of the cylinder opposite the one receiving the maximum thrust of the piston. The maximum amount of wear was usually on the sides of the cylinder in line with the engine, although in a very few cases the maximum wear was on the thrust face of the cylinder. Table 2 shows the average wear of five engines with ref-

TABLE 2. Wear on circumference of cylinder, average for five engines

\begin{tabular}{|c|c|c|c|c|c|}
\hline Position on cylinder & $\begin{array}{c}\text { Engine 1, } \\
\text { a verage } \\
\text { wear }\end{array}$ & $\begin{array}{c}\text { Engine 2, } \\
\text { a verage } \\
\text { wear }\end{array}$ & $\begin{array}{c}\text { Engine 3, } \\
\text { average } \\
\text { wear }\end{array}$ & $\begin{array}{c}\text { Engine 4, } \\
\text { a verage } \\
\text { wear }\end{array}$ & $\begin{array}{l}\text { Engine 5, } \\
\text { a verage } \\
\text { wear }\end{array}$ \\
\hline Thrust_. & $\begin{array}{c}\text { in. } \\
0.000074\end{array}$ & $\stackrel{i n .}{0.000060}$ & $\begin{array}{c}\text { in. } \\
0.000032\end{array}$ & $\begin{array}{c}\text { in. } \\
0.000050\end{array}$ & $\begin{array}{l}i n . \\
0.000070\end{array}$ \\
\hline Front & .000098 & .000066 & .000048 & .000067 & .000097 \\
\hline Antithrust. & .000034 & .000028 & .000031 & .000052 & .000095 \\
\hline Rear........ & .000084 & .000058 & .000067 & .000066 & .000088 \\
\hline
\end{tabular}

erence to the position of the marks on the cir cumference of the cylinder.

An 18-percent correction was made for metal springback in the indentation, and an average correction of 5 percent was used for curvature of the cylinder wall. Most values are averages of 240 or more readings and represent at least 10 weeks of engine operation.

A definite vertical pattern of cylinder wear was found to exist with all of the engines tested. This is shown graphically in figure 10 and in table 3 below. This table is a general average of the wear by levels in the cylinder in a large number of tests made with gasoline and alcohol. Each value in the table is an average of the results of

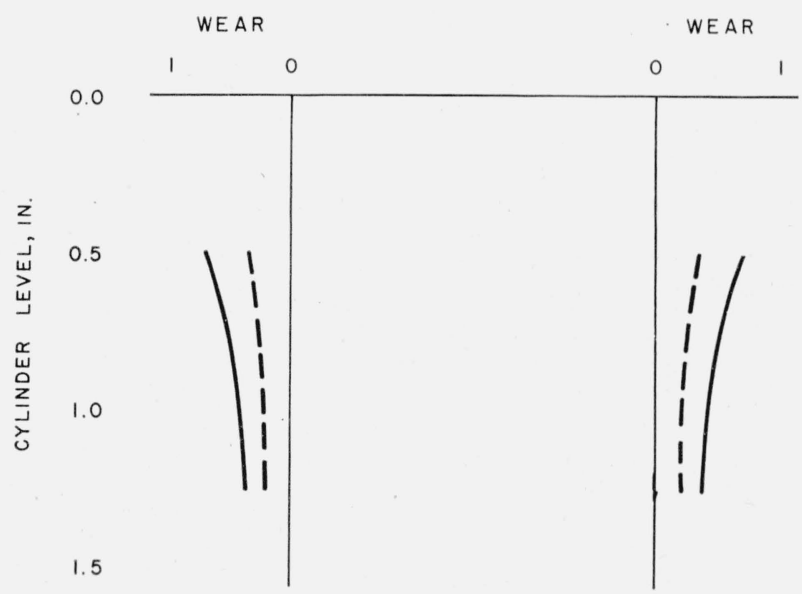

Figure 10. Vertical wear pattern in engine cylinder.

Units of wear at top of figure are ten-thousandths of an inch. Dotted lines indicate wear with alcohol, solid lines gasoline. 
TABLE 3. Wear by cylinder levels with alcohol and gasoline

All measurements were made in the upper one-third of piston travel

\begin{tabular}{|c|c|c|c|}
\hline Distance to top of cylinder & $\begin{array}{l}\text { Average } \\
\text { wear with } \\
\text { gasoline a }\end{array}$ & $\begin{array}{l}\text { Average } \\
\text { wear with } \\
\text { alcohol b }\end{array}$ & $\begin{array}{l}\text { Alcohol } \\
\text { wear, } \\
\text { percentage } \\
\text { of gasoline } \\
\text { wear }\end{array}$ \\
\hline $\begin{array}{c}\text { in } \\
1 / 2 \\
1 / 4 \\
11 / 4\end{array}$ & $\begin{array}{c}\text { in } \\
0.000078 \\
.000057 \\
.000047 \\
.000041\end{array}$ & $\begin{array}{c}\text { in } \\
0.000039 \\
.000030 \\
.000024 \\
.000024\end{array}$ & $\begin{array}{l}50 \\
53 \\
51 \\
58\end{array}$ \\
\hline
\end{tabular}

a A verage of 4,200 readings.

b Average of 936 readings.

tests made on all engines. The corrections for cylinder wall curvature and metal springback are the same as in table 2 .

\section{Factors Affecting Wear}

During the course of the investigation it was observed that the amount of wear varied considerably with changes in operating conditions. As these variations did not always seem consistent, surveys of test conditions were made for a comparatively long operating period, with particular reference to operating temperatures, humidity, starting, etc. In regard to this survey, the following conditions were considered significant. (1) At low operating temperatures, wear appeared to be greatly accelerated. In figure 11 the wear in all tests made with five engines on gasoline is plotted against the temperature of the cooling water circulated through the engine during the 10-min. stopping period of each half-hour cycle. Although

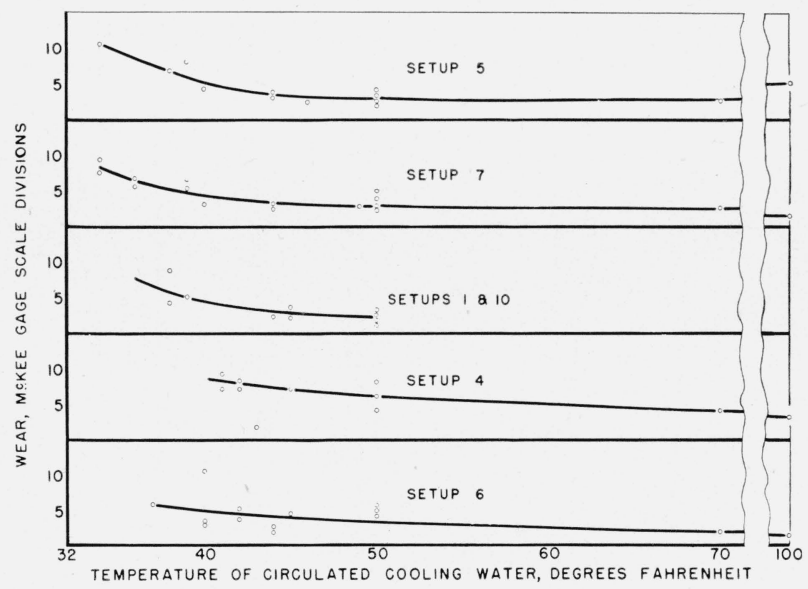

FiguRE 11. Relation of wear to temperature of circulated cooling water. there is a considerable scatter of the points, it is seen that there is a definite trend toward increased wear as the temperature was decreased below about $50^{\circ} \mathrm{F}$. The decrease in wear as the temperature is increased beyond this point appears to be small, but it does seem to continue up to $100^{\circ}$ $\mathrm{F}$, the highest temperature used in these tests. In two tests where the engines were operated continuously, without the usual $10-\mathrm{min}$. stop for cooling in each half-hour, the wear was found to be negligible. Presumably most of the wear in the other tests must have occurred during the engine warmup. (2) During starts made at very low temperatures, wear was found to be greatly accelerated. Indentations of the usual length (about $1 \mathrm{~mm}$ ), made on the cylinder walls of an engine used only in starting tests at low temperatures, had completely disappeared after a total operating time of a little more than $200 \mathrm{hr}$. In these tests the engine was started at atmospheric temperatures ranging from $+60^{\circ}$ to $-25^{\circ} \mathrm{F}$ and was operated until the engine temperatures had reached equilibrium. The rate of wear in this case was at least six times as great as the maximum found in the usual test cycle at $34^{\circ} \mathrm{F}$ or above. (3) No definite relation of wear to atmospheric humidity could be established. (4) Some fuels are more corrosive to the engine than are others (see table 3). In this connection, Williams [10] showed that wear is much accelerated by high sulfur content of the fuel.

The cause of the increase in wear at low operating temperatures is not definitely known. One theory advanced $[11,12,13,14]$ is that there is a deficiency in lubrication during starting and engine warmup. This may be due to a delay in the lubricant reaching the cylinder wall or to loss in viscosity of the lubricant through dilution. A second theory holds that the wear at low engine temperatures is due to corrosion $[10,13,15]$. Williams believed that low temperatures permitted the condensation of moisture on the cylinder walls, thus favoring the formation of corrosive acids. He pointed out that wear was greatly accelerated when the temperature of the cylinder walls was just below the dewpoint. Further support for the corrosion theory is found in the results shown in table 3. The wear with alcohol fuels was found to be about half that with gasoline in tests made under comparable conditions. It is reasonable to assume that the difference in wear may have been 
due to differences in the corrosive characters of the fuels.

It is improbable that much corrosion occurs during the actual stop. Studies have shown [16] that the corrosion film formed on iron tends to protect the surface from further corrosion, unless this film is removed by mechanical means as by piston rings during operation of an engine. Further support for the theory that corrosion occurs during the warmup is found in the fact that the test engines were connected to heavy dynamometers or generators, so that when switched off they rotated a number of revolutions before stopping. In this way the cylinders were left filled with a mixture of fuel and air that was not particularly corrosive. During the warmup a considerable number of explosions occur before the temperature of the walls is raised above the condensation point. The dewpoint temperature for exhaust gas [10] is about $126^{\circ} \mathrm{F}$ at atmospheric pressure and about $300^{\circ}$ $\mathrm{F}$ at $500 \mathrm{lb} /$ in. $^{2}$, approximately the maximum pressure reached in an automotive engine. It is seen in figure 9 that with the circulated tap water at $52^{\circ} \mathrm{F}$ approximately $4 \mathrm{~min}$ of operation was required to raise the water jacket to $140^{\circ} \mathrm{F}$, the temperature generally accepted by the automotive industry as the minimum for satisfactory operation.

Assuming that $4 \mathrm{~min}$ of the cycle would be required for the engine to reach the dewpoint temperature, there would be more than 2,500 explosions in each cylinder that might be followed by condensation of corrosive gases, and more than 10,000 strokes of the piston during which the piston rings would wipe oil and corroded material from the cylinder wall. In successive strokes of the piston there would be further corrosion that would in turn be wiped off so that more corrosion could take place.

It should be observed that these tests were run in a laboratory where there was comparative freedom from dust and other abrasive materials ordinarily picked up in road operation.

Sparrow and Scherger point out [11] that much wear results from faulty distribution of cooling water. This may result in condensation from too low a wall temperature or in hot spots that cause the oil to lose its viscosity. It was observed that in some of the engines tested at the National Bureau of Standards the front cylinders (nearest the water pump) always had a greater wear than any of the other cylinders.

Further discussion of the cause of wear is given by Williams, who made an extensive review of the literature [17 to 28] on the subject. In view of the above evidence, it is therefore believed that a considerable part of cylinder wear may be due to the corrosion occurring during the engine warmup when condensation on the cylinder walls is possible. The wear might be much reduced if the jacket temperatures could be kept above the dewpoint or if some method could be developed to make the cylinders, pistons, and rings completely corrosion resistant.

\section{Combustion Chamber Deposits}

After each 144-hr run, the deposits of carbon were carefully removed from the cylinder head, valves, and engine block. The deposits were weighed and extracted with naphtha to remove traces of oil and moisture remaining and were analyzed for iron and lead. The iron in a weighed and dried sample is first dissolved in a mixture (1:5) of nitric and sulfuric acids, then precipitated as a hydroxide, dissolved in $6 \mathrm{~N}$ hydrochloric acid and determined by titration with potassium dichromate after reduction with stannous chloride. The total amount of noncombustible ash is determined by heating a weighed sample of the engine deposits at about $1,000^{\circ} \mathrm{C}$ to constant weight The remainder of the sample is assumed to be carbonaceous material.

A total of 49 samples were weighed and analyzed. The samples represented 62 weeks of engine operation. The analyses are summarized in table 4.

TABLE 4. Combustion chamber deposits

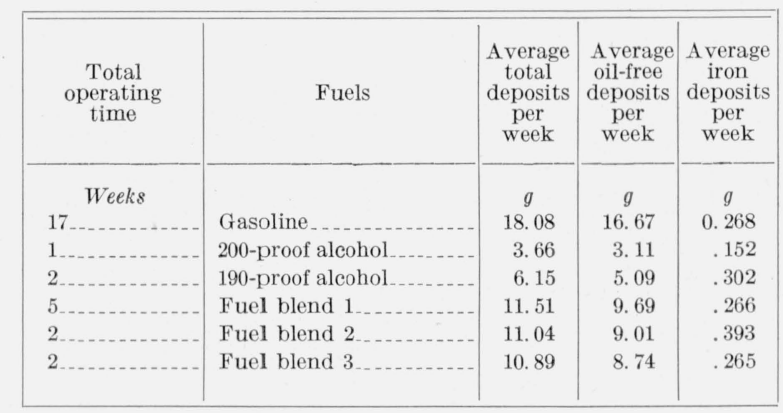

It is shown that the combustion chamber deposits are considerably less with 190-proof and 
200-proof alcohols than with gasoline. Experimental work has indicated that most engine deposits are due to incomplete combustion of the lubricating oil [29]. It is therefore believed possible that the smaller carbon deposits occur with alcohol and its blends because of the fact that there is no dilution of the oil such as occurs with gasoline. When the lubricant is diluted with gasoline it loses much of its viscosity, so that presumably more of it can reach the cylinders, making more engine deposits possible. The differences in iron deposits may be due to metal removed from the cylinder head, etc., by the sampling tools. Consequently the amount of iron has no significance.

\section{Analysis and Consumption of Lubri- cating Oil}

Twenty-eight samples of crankcase oils from engines operating on gasoline and alcohol were analyzed. There was no indication of dilution of the lubricant by an alcohol fuel. Gasoline shows a dilution of 2 percent by weight, estimated by ASTM method D-322-35. The ASTM method employs steam distillation and is not applicable to crankcase oils from engines operating on alcohol and other water soluble fuels.

The percentage by weight dilution of the alcohols was based on the loss by evaporation upon heating for two $1-\mathrm{hr}$ periods at $105^{\circ} \mathrm{C}$, and the results were compared with a sample of new oil. This method was not satisfactory for gasoline, as it involved prolonged heating with an uncertain endpoint.

Five engines were in operation over the period during which the oil consumption was taken, but due to the fact that in most of the tests the engines

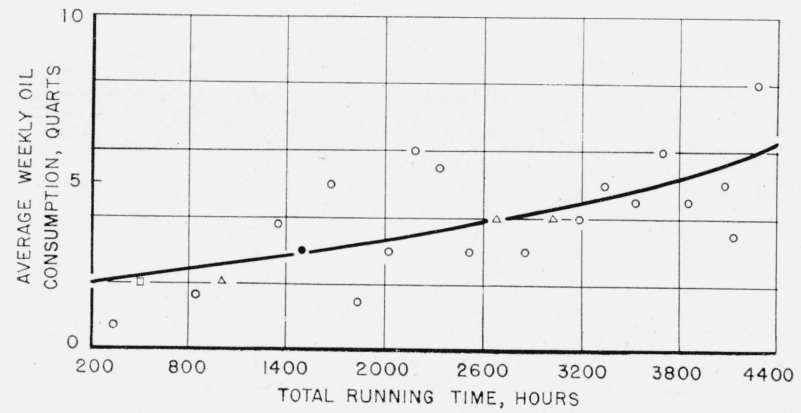

Figure 12. Oil consumption of wear-test engine with various fuels.

O, Gasoline; $\triangle$, 190-proof alcohol; $\bullet$ fuel 1; $\square$, 200-proof alcohol. were operated on gasoline, some of the data on the other fuels may not be representative of average conditions. Figure 12 shows the average oil consumption of one of the engines in which a number of tests were made with each fuel. These tests gave no indication that there was any significant difference between the oil consumption in operation with gasoline or alcohol fuels.

\section{Operating Temperature Limits of Blends}

The starting lines shown in figure 13 were taken from data reported by R. E. Streets [6]. It is shown that starting is possible at temperatures somewhat below normal winter temperatures in this country if ether is used in the alcohol blend, but vapor lock results at fairly low temperatures. Acetone is not as good as ether in lowering the minimum starting temperature, but it is not as likely to cause vapor lock.

Vapor lock is partial or complete interruption of fuel flow due to formation of vapors in the fuel lines or carburetor. The net result of vapor lock is a considerable increase in the leanness of the mixture ratio. This is usually indicated by one or more of the following phenomena: (1) Loss of power, (2) backfiring and/or surging, (3) abnormally high engine temperatures, (4) detonation and (5) complete stoppage of the engine or failure to start. Closely related to vapor lock is another hot weather fuel trouble, carburetor percolation. This is the result of the accumulation of excessive quantities of vapor in the carburetor bowl. It usually occurs during idling or during a stop with ignition off after a hard run, and is evidenced by stalling of the engine during idling or by difficulty in starting because of an over-rich mixture.

Unblended 190-proof alcohol is not subject to vapor lock at any atmospheric temperature likely to be encountered. However, it cannot be used for starting at temperatures much below $60^{\circ} \mathrm{F}$ unless it is blended with a more volatile fuel. In order to determine the permissible fuel volatility for adequate starting with reasonable freedom from vapor lock, a series of tests was run with a 1942 model automobile. The test car was equipped with nickel resistance thermometers for measurement of temperatures of outside air, carburetor air, fuel in the carburetor bowl, carburetor flange, fuel in tank, water jacket, and crankcase oil. A gage was 
connected to the fuel line to indicate pump discharge pressure. Fuel from the tank was sampled at intervals through a coil packed in dry ice so that no vapors would be lost in sampling. The test procedure was to (1) charge the fuel tank with alcohol to which a volatile blending agent had been added in proportions estimated to cause vapor lock; (2) drive the car at $50 \mathrm{mph}$ for $1 \mathrm{hr}$, taking readings of the temperatures in the fuel system, etc., at 15-min intervals; (3) stop the car facing the wind and the engine idling; (4) read temperatures of nickel resistors 4 min after stop and turn off ignition $5 \mathrm{~min}$ after the stop; (5) take another set of readings $14 \mathrm{~min}$ after the ignition was switched off, restart the engine 1 min later; and (6) get the car into high gear as soon as possible and attempt to accelerate with wide open throttle. Cutting out of the engine due to lack of fuel was considered an indication of vapor lock. A further indication of vapor lock was a fall of the fuel-pump pressure to zero.

If the system did not vapor lock, more of the volatile blending agent was added to the fuel, the car was driven about 6 miles at 50 miles per hr, and the above procedure was repeated. Further additions of the blending agent were made until vapor lock occurred. Samples of each fuel blend with which the engine was operated were taken for laboratory study. The Reid vapor pressure was measured by ASTM method D 323-41. The refractive indices of the samples were determined so that the composition of the blends could be estimated.

Control tests were made to determine the operating characteristics of the test car using blends of gasoline and isopentane. Vapor lock occurred at an atmospheric temperature of $100^{\circ} \mathrm{F}$ with a blend having a Reid vapor pressure of $7.3 \mathrm{lb} / \mathrm{in}^{2}{ }^{2}$. This is considered as a normal vapor-locking tendency. As the carburetor used in the tests had a mixture control, this carburetor was replaced with a standard carburetor after incipient vapor lock was obtained and the test repeated with the same result, indicating that the use of the special carburetor did not change the vapor-locking tendency of the car.

The Reid vapor pressure of the alcohol blend that gave vapor lock at $100^{\circ} \mathrm{F}$ is low as compared with that of gasoline being $3.5 \mathrm{lb} / \mathrm{in}^{2}$ for the blend and $7.3 \mathrm{lb} / \mathrm{in}^{2}$ for gasoline. Due to the fact that the Reid method is designed for a $V / L$ ratio of 4 and the vapor handling capacity of the car is about 30, comparisons cannot be made of fuels whose $V / L$ relations are as different as those of alcohol and gasoline. The data on the alcohol blends are therefore presented in volume percentage of the blend rather than giving the Reid vapor pressure.

The results of the tests are shown graphically in figure 13. The useful operating range of a

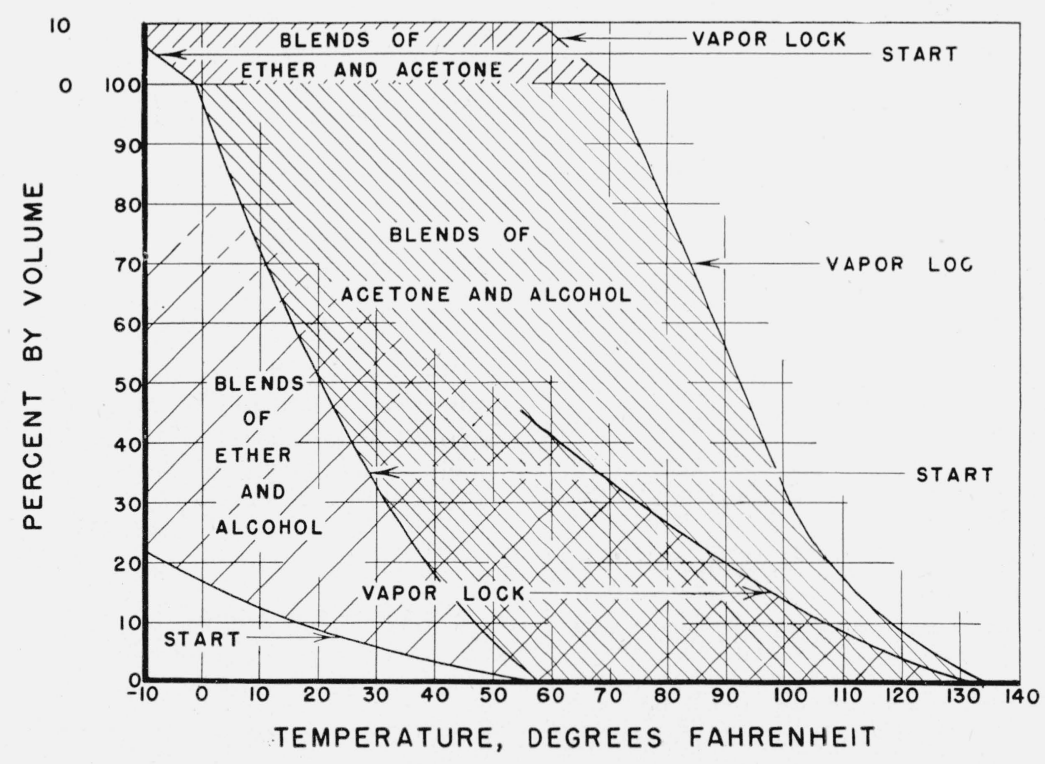

FIGURE 13. Operating limits of alcohol blends with ether and acetone. The blending agent is the first of each pair. The temperatures are atmospheric temperatures. 
blend containing any given percentage of a blending agent is indicated on figure 13 by the abscissae of the points at which the percentage line indicated intersects the lines for starting temperature and vapor lock. The lines for minimum starting temperature and vapor lock are the heavy lines that cross the page diagonally. For example the ordinate for 10-percent ether in alcohol crosses the lines for starting and vapor lock at points that indicate that starting is possible at $16^{\circ} \mathrm{F}$, while vapor lock will occur at $107^{\circ} \mathrm{F}$. It will be seen that small percentage of ether will lower the starting temperature somewhat more than the same percentage of acetone. The useful range of a blend containing 10-percent ether in alcohol is from $16^{\circ}$ to $100^{\circ} \mathrm{F}$, or 84 degrees. Sixty percent of acetone must be added to alcohol before an engine can be started at $16^{\circ} \mathrm{F}$, and the blend will cause vapor lock at $88^{\circ} \mathrm{F}$, a useful range of 72 degrees. Therefore, disregarding cost and availability, ether is a better blending agent for alcohol than is acetone.

\section{Conclusions}

This series of tests indicates that 190-proof alcohol blended with ether for starting at low temperatures is a satisfactory substitute for gasoline. In general, power and engine performance are comparable for the two fuels. Fuel system parts are not adversely affected by alcohol or ether.

The relative rate of evaporation, combustion chamber deposits, and crankcase oil dilution are less with alcohol than when operating on gasoline.

The disadvantages of using alcohol are that the range of atmospheric temperatures for operation is less than with gasoline, and that larger quantities of the more expensive fuel (alcohol) are required.

\section{References}

[1] Donald B. Brooks, J. Research NBS 35, 1 (1945) RP1660.

[2] Afton D. Puckett, J. Research NBS 35, 273 (1945) RP1673.

[3] Jesse T. Duck and C. S. Bruce, J. Research NBS 35, 439 (1945) RP1681.

[4] F. A. Middleton and C. S. Bruce, J. Research NBS 36, 171 (1945) RP1698.

[5] Donald B. Brooks, J. Research NBS 36, 425 (1945) RP1712.

[6] R. E. Streets, J. Research NBS 39, 39 (1947) RP1811.

[7] George Beck, Zylinder und Kolbenring Verschleiss Deutsche Kraftfahrtforschung 29 (1939).
[8] Frederick Knoop, Chauncey G. Peters, and Walter B. Emerson, J. Research NBS 23, 39 (1939) RP1220.

[9] S. A. McKee, J. Research NBS 39, 155 (1947) RP1819.

[10] C. G. Williams, Collected researches on cylinder wear (British Institution of Automobile Engineers, London, 1940).

[11] S. W. Sparrow and T. A. Scherger, SAE J. 38, 117 (1936).

[12] Frank Jardine, Automotive Ind. 51, 242 (1924).

[13] Otto M. Burkhardt, SAE J. 19, 657 (1926).

[14] A. E. Becker, Automotive Ind. 64, 401 (1931).

[15] GMC Research Staff, Automotive Ind. 50, 956 (1924).

[16] U. R. Evans, Metallic corrosion, passivity, and protection E. Arnold, \& Co., (London, 1937).

[17] C. E. Summers, SAE J. 16, 243 (1925).

[18] Symposium, SAE Summer Meeting, June 27, 1924, SAE J. 15, 10 (1924).

[19] A. H. Hoffman, SAE J. 25, 625 (1929).

[20] Symposium, Baltimore SAE Section Meeting, SAE J. 2\%, 518 (1930).

[21] E. J. Lowery, SAE J. 20, 277 (1927).

[22] E. Zimmerman, Metals \& Alloys 2, 95 (1931).

[23] E. Piwowarsky, Giesserei-Ztg. 24, 553 (1927).

[24] N. Stern, Motorwagen 99, 479 (1926).

[25] Anonymous, Metallurgist 7, 132 (1931).

[26] H. Bornstein, ASTM Proc. 20, part II, 166 (1929).

[27] Gusseisen, Z. Ver. deut. Ing. (1930).

[28] Staff of the John I. Thorncraft Co., Nickel Bul. (London) 4, 295 (1931).

[29] Donald B. Brooks, SAE J. 18, 48 (1926).

\section{Appendix}

\section{Mathematical Relationships in the Indentation}

The angle at the apex of the diamond used in the tests was $171^{\circ} 26^{\prime}$. The sum of the angles $\delta$ and $\theta$ in both triangles of figure 5 is therefore $8^{\circ} 34^{\prime}$. In $3 A,\llcorner\delta=\llcorner\theta$ and the depth of the indentation may be determined by the equation

$$
\left.\begin{array}{l}
d_{A}=a_{A} \tan \theta \\
a_{A}=\frac{d_{A}}{\tan \theta}
\end{array}\right\}
$$

In the above equations, and those that follow, the subscript $A$ denotes a symmetrical indentation and the subscript $B$ denotes an asymmetrical indentation. The amount of rotation of the indenter is indicated by the angle $\rho$ included between $d$ and $l$

By the law of sines

$$
\left.\begin{array}{c}
\delta_{B}=\theta_{A}-\rho \\
\theta_{B}=\delta_{A}+\rho
\end{array}\right\}
$$

$$
\begin{gathered}
\frac{a_{B}}{b_{B}}=\frac{\sin \left(\theta_{A}+\rho\right)}{\sin \left(\theta_{A}-\rho\right)} \\
a_{B}=b_{B} \frac{\sin \left(\theta_{A}+\rho\right)}{\sin \left(\theta_{A}-\rho\right)}
\end{gathered}
$$


The sine ratio,

$$
\frac{\sin \left(\theta_{A}+\rho\right)}{\sin \left(\theta_{A}-\rho\right)}
$$

may be expressed as $R$, so $a_{B}=b_{B} R$.

$$
\begin{gathered}
a_{A}=b_{A}, 2 b_{A}=b_{B}+b_{B} R=b_{B}(1+R) . \\
l_{B}=a_{B} \frac{\sin \left(\theta_{A}-\rho\right)}{\sin \alpha} \\
d_{B}=l_{B} \cos \rho=\frac{a_{B} \sin \left(\theta_{A}-\rho\right) \cos \rho}{\sin \alpha} \\
b_{A}=b_{B} \frac{(1+R)}{2}
\end{gathered}
$$

and

$$
\begin{gathered}
d_{A}=b_{B} \frac{(1+R) \tan \theta_{A}}{2} \\
\frac{d_{B}}{d_{A}}=\frac{\frac{a_{B} \sin \left(\theta_{A}-\rho\right) \cos \rho}{\sin \alpha}}{b_{B} \frac{(1+R) \tan \theta_{A}}{2}} \\
a_{B}=b_{B} R,
\end{gathered}
$$

so

$$
\frac{d_{B}}{d_{A}}=\frac{2 R \sin \left(\theta_{A}-\rho\right) \cos \rho}{(1+R) \tan \theta_{A} \sin \alpha}
$$

Substituting for $R$,

$$
\begin{aligned}
\frac{d_{B}}{d_{A}} & =\frac{\frac{\sin \left(\theta_{A}+\rho\right) \sin \left(\theta_{A}-\rho\right) \cos \rho}{\sin \left(\theta_{A}-\rho\right)}}{\frac{\left[\sin \left(\theta_{A}-\rho\right)+\sin \left(\theta_{A}+\rho\right)\right] \tan \theta_{A} \sin \alpha}{\sin \left(\theta_{A}-\rho\right)}} \\
& =\frac{2 \sin \left(\theta_{A}+\rho\right) \sin \left(\theta_{A}-\rho\right) \cos \rho}{\left[\sin \left(\theta_{A}-\rho\right)+\sin \left(\theta_{A}+\rho\right)\right] \tan \theta_{A} \sin \alpha} \cdot
\end{aligned}
$$

Expanding

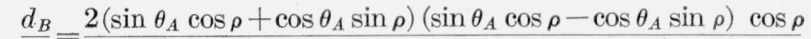
$\overline{d_{A}}=\frac{2\left(\sin \theta_{A} \cos \rho-\cos \theta_{A} \sin \rho+\sin \theta_{A} \cos \rho+\cos \theta_{A} \sin \rho\right) \tan \theta_{A} \sin \alpha}{(\sin }$

Simplifying

$$
\frac{d_{B}}{d_{A}}=\frac{\sin ^{2} \theta_{A} \cos ^{2} \rho-\cos ^{2} \theta_{A} \sin ^{2} \rho}{\sin \theta_{A} \tan \theta_{A} \sin \alpha} .
$$

But

$$
\alpha=90-\theta_{A},
$$

and

$$
\sin \alpha=\cos \theta_{A}
$$

$$
\tan \theta_{A}=\frac{\sin \theta_{A}}{\cos \theta_{A}}
$$

so substituting, we find that

$$
\left.\begin{array}{rl}
\frac{d_{B}}{d_{A}} & =\frac{\sin ^{2} \theta_{A} \cos ^{2} \rho-\cos ^{2} \theta_{A} \sin ^{2} \rho}{\sin ^{2} \theta_{A}} \\
& =\cos ^{2} \rho-\frac{\cos ^{2} \theta_{A}}{\sin ^{2} \theta_{A}} \sin ^{2} \rho=\cos ^{2} \rho-\operatorname{ctn}^{2} \theta_{A} \sin ^{2} \rho \\
& =1-\sin ^{2} \rho-\operatorname{ctn}^{2} \theta_{A} \sin ^{2} \rho \\
& =1-\left(1+\operatorname{ctn}^{2} \theta_{A}\right) \sin ^{2} \rho
\end{array}\right\}
$$

The difference between the depths of the symmetrical and asymmetrical indentations is expressed by the equation

$$
1-\frac{d_{B}}{d_{A}}=\left(1+\operatorname{ctn}^{2} \theta_{A}\right) \sin ^{2} \rho .
$$

If $\theta_{A}=4^{\circ} 17^{\prime}, \operatorname{ctn}^{2} \theta_{A}=178.22$ and $1-\frac{d_{B}}{d_{A}}=179.22 \sin ^{2} \rho$.

Using the equation above and the sine ratio from eq 5 , a corrcetion chart for asymmetrical indentations may be set up, as shown in table 5. As the sine ratio is the same as the ratio of the visible segments of the mark, $a$ and $b$, the angle of rotation, $\rho$, is determined from the ratio $a / b$

TABLE 5. Correction chart for asymmetrical indentations if $\theta_{A}=4^{\circ} 17^{\prime}$

The correction for asymmetry is found by comparison of columns 2 and 3

\begin{tabular}{|c|c|c|}
\hline $\begin{array}{c}\text { Angle of rota- } \\
\text { tion of } \\
\text { indenter }\end{array}$ & Ratio of $a / b^{a}$ & $\begin{array}{c}\text { Correction for } \\
\text { asymmetry }\end{array}$ \\
\hline & & \\
\hline & & Percent \\
0.0 & 1.000 & 0.0000 \\
.1 & 1.048 & .0546 \\
.2 & 1.098 & .218 \\
.3 & 1.150 & .490 \\
.4 & 1.206 & .87 \\
.5 & 1.264 & 1.36 \\
.6 & 1.325 & 1.96 \\
.7 & 1.390 & 2.68 \\
.8 & 1.458 & 3.50 \\
.9 & 1.531 & 4.42 \\
1.0 & 1.608 & 5.46 \\
\hline
\end{tabular}

a Also ratio of $\sin \theta / \sin \delta$.

Washington, June 12, 1947. 